\title{
Perspectivas para o currículo da Educação de Jovens e Adultos: dinâmicas entre os conhecimentos do cotidiano e da ciência
}

\begin{abstract}
Claudia Barcelos de Moura Abreu* Claudia Lemos Vóvio**

\section{Resumo}

Este artigo tem por objetivo apresentar alguns dos desafios na organização de currículos da escolarização de pessoas jovens e adultas, de modo a se cumprir as metas educacionais postuladas para essa modalidade de ensino e efetivar o direito à educação para todos os cidadãos. Interessa investigar, por meio de análise documental, como um conjunto de princípios norteadores que emergiram do campo da educação popular e que indicam um certo acúmulo de conhecimentos para a produção de currículos na área pode ser observado, tomando como referência empírica as bases de um currículo voltado à educação de jovens e adultos (EJA). Igualmente, pretende-se verificar como se apresentam, no documento, as relações entre conhecimentos do cotidiano e os conhecimentos científicos. Os resultados obtidos por esta análise mostram que há uma apropriação das principais categorias do campo da EJA para pensar o novo currículo, mas é possível perceber que a relação entre conhecimentos cotidianos e científicos precisa ainda ser trabalhada de forma mais rigorosa, considerando a função social da escola.
\end{abstract}

Palavras-chave: Educação de jovens e adultos. Escolarização. Organização curricular.

\section{Perspectives to the youth and adult education curriculum: dynamics between quotidian and scientific knowledges}

\begin{abstract}
The aim of this paper is to present some challenges related to curriculum organization for the youth and adult schooling process, considering the achievements of educational goals demanded to this learning modality and the guarantee of the education right for all citizens. It is interested in investigating, by document analysis, how a set of principles that emerged from the popular education field and that showed an increase of knowledge construction could be analyzed considering the empirical basis of a curriculum directed to youths and adults. Equally, it intends to verify how the relationship between quotidian and
\end{abstract}

\footnotetext{
* Professora Doutora da Universidade Federal de São Paulo (UNIFESP). São Paulo, Brasil.
}

** Professora Doutora da Universidade Federal de São Paulo (UNIFESP). São Paulo, Brasil. 
scientific knowledges is presented in the document. The results show an appropriation of the main categories of the youth and adult education to think the new curriculum, but it is possible to realize that the relationship between quotidian and scientific knowledges needs to be studied deeply, considering the social function of the school.

Keywords: Youth and adult education. Schooling. Curriculum organization.

\section{Introdução}

O presente artigo tem por objetivo focalizar alguns dos desafios implicados na organização de currículos, especialmente as escolhas necessárias para se definir quais versões da cultura e quais conhecimentos devem estar presentes no processo de escolarização de pessoas jovens e adultas de modo a tanto cumprir com as metas educacionais postuladas para essa modalidade de ensino como efetivar o direito à educação para todos os cidadãos. Como uma modalidade educativa, a Educação de Jovens e Adultos (doravante EJA) constitui-se em meio para promover a escolarização para aqueles que, por algum motivo, ficaram fora desta. A escola para os sujeitos jovens e adultos é vista como território socialmente instituído para mediar esse processo que compreende o acesso a bens produzidos ao longo da história da humanidade e a modelos culturais de ação, fundados em saberes, valores, práticas e outros referentes. É também locus privilegiado de produção, circulação e consolidação de significados, de conhecimentos, que, como bem alerta Costa (1998), se encontram no jogo social em condição de disputa: "quem tem força nessa política impõe ao mundo suas representações, o universo simbólico de sua cultura particular" (p. 38).

A efetivação do direito à educação com qualidade aos jovens e adultos é ainda um grande desafio, como nos mostra o panorama da educação nacional. Durante a maior parte de sua história a EJA esteve relacionada de modo restrito à alfabetização e sob forte influência de duas concepções dicotômicas, ambas permeadas pela correlação entre educação e mudança social.

Uma dessas concepções é a educação compensatória, orientada para recuperar o "atraso"1 educativo de pessoas que não puderam estudar em idade "própria", com fortes traços do modelo e formato da educação regular. O paradigma compensatório no campo legal, segundo Di Pierro (2005), impregna a EJA desde a criação do ensino supletivo (em 1971), enclausurando essa modalidade "nas rígidas referências curriculares, metodológicas, de tempo e espaço da escola de crianças e adolescentes, interpondo obstáculos à flexibilização da organização escolar necessária ao atendimento das especificidades desse grupo sociocultural" (DI PIERRO, 2005, p. 1118). Outro efeito negativo desse paradigma é a perspectiva assistencialista adotada em programas de EJA, apontada por 
Fávero, Rummert e De Vargas (apud RIBEIRO, 1999, p. 189), concebendo-a "como uma ação de caráter voluntário, marcado por um cunho de doação, favor, missão, e movida pela solidariedade tal como concebida na perspectiva liberal de ajuda aos mais pobres, de caridade para com os desfavorecidos".

Outra concepção é a educação como meio de emancipação e transformação das pessoas e sociedades, advindas das experiências de Paulo Freire e continuadas no território da educação popular (ARROYO, 2005; KALMAN, 2000). O paradigma emancipatório e as experiências inovadoras de alfabetização e de EJA constituem-se no legado da educação popular, porém com repercussões ainda tênues nos sistemas de ensino. Alguns dos discursos advindos de uma perspectiva emancipatória colocam-se como receosos diante do processo de institucionalização da EJA, "desconfiam que a escolarização, como espelho na escola atual, é a morte do sentido político e pedagógico para a EJA" (HADDAD, 2007 p. 16). Outros, no entanto, defendem a escolarização como efetivação do direito humano à educação e via para adquirir conhecimentos que tanto abarcam as necessidades desse segmento perante o mundo do trabalho como possibilitam a continuidade dos estudos.

Ultrapassar dicotomias e definir o papel da educação escolar para pessoas jovens e adultas, bem como estabelecer currículos para a educação escolar pública com a meta de integrar plenamente grupos estigmatizados e destituídos de seus direitos educativos, são algumas problemáticas para as quais uma perspectiva emancipatória e sensivelmente cultural tem tentado responder. As produções de inúmeros pesquisadores e as experiências no campo da educação popular a partir dos postulados humanistas e críticos de Freire têm feito emergir e reiterar princípios produtivos para a construção e concretização de currículos orientados para essa perspectiva. Destacamos, por exemplo, o (re)conhecimento da realidade social dos educandos e das comunidades onde esses programas estão inseridos; a valorização das experiências prévias dos educandos e dos patrimônios culturais construídos fora do âmbito escolar e de modos muito variados, a reorganização dos conteúdos escolares, a ressignificação dos processos de avaliação, com foco na aprendizagem e com novos formatos, a investigação sobre as reais necessidades de aprendizagem dos sujeitos, entre outros.

A seguir, apresentamos algumas considerações sobre os sujeitos da EJA, pois acreditamos que compreender esse segmento em suas singularidades e semelhanças colabora para refletir sobre como integrar seus patrimônios culturais produzidos em diversos âmbitos sociais à função específica que a escola assume diante dos saberes veiculados.

\section{Homogeneidade e heterogeneidade dos sujeitos da EJA}

Podemos dizer que uma das principais especificidades da modalidade EJA refere-se ao perfil de seus educandos - às pessoas para a qual essa 
modalidade educativa se dirige. Do ponto de vista social, há alguns elementos que as aproximam, como demonstram os dados obtidos em pesquisas sociodemográficas. Segundo dados da Pesquisa Nacional para Amostra de Domicílios (PNAD) (IBGE, 2007), há cerca de 14 milhões de pessoas com quinze anos e mais que não estão alfabetizadas.

Estratificando-se os dados em diferentes planos, veremos que o fenômeno do analfabetismo reflete as desigualdades sociais existentes em nosso país. O fenômeno social do analfabetismo tende a tornar-se mais agudo nos grupos sociais em maior condição de vulnerabilidade social. Se tomarmos como parâmetros os números indicados pelo Censo Demográfico, observamos que em determinadas regiões do país a redução do analfabetismo é um desafio mais difícil de enfrentar do que em outras: na Região Nordeste, em 2007, o índice de analfabetismo era de 20\%; já na Região Sul, caía para 5,4\%; nas zonas rurais do país, $23,3 \%$ dos jovens e adultos eram analfabetos, enquanto nas zonas urbanas esse índice era de 4,4\%.

Entre a população negra, a taxa de analfabetismo era de 14,1\%, contra 6,1\% da branca, revelando a distribuição desigual de oportunidades de acessar serviços sociais e bens culturais desse segmento da população.

O maior contingente de analfabetos encontrava-se nos grupos etários mais idosos, com idade acima de 40 anos. Mas isso não quer dizer que o analfabetismo esteja restrito aos idosos: em 2007, cerca de 2 milhões de jovens com idade entre 15 e 29 anos eram analfabetos.

Os dados em relação aos anos de estudo também são preocupantes, a taxa média brasileira atingiu 7,3 anos, tendo como extremos as regiões Sudeste (8 anos) e Nordeste (6 anos). Desse modo, apenas a primeira região atingiu, ao menos em termos médios, a escolarização mínima obrigatória de 8 anos de estudos, estabelecida pela Constituição Federal de 1988.

Se, por um lado, os números do analfabetismo e dos níveis de escolarização da população nos dão a dimensão do desafio educacional brasileiro, por outro, nos dizem muito pouco sobre quem são estas pessoas, como elas vivem, o que sabem, o que significa para elas não saber ler e escrever, o que querem aprender.

Durante um longo período do século passado, uma perspectiva discriminatória e dicotômica permeou grande parte dos discursos sobre a importância da educação escolar e aquisição da escrita, argumentavam-se que ambas promoveriam o desenvolvimento político, econômico, científico das sociedades e seriam um sinônimo de progresso social; e, no âmbito individual, seriam responsáveis pelo desenvolvimento cognitivo das pessoas e pela aquisição de um conjunto de habilidades e conhecimentos necessários para inserção em sociedades modernas, burocráticas e letradas, como a nossa. Foram atribuídos 
à escolarização e à linguagem escrita efeitos homogêneos e universais responsáveis pela transformação das sociedades e da mente humana. Tais atribuições encontravam-se baseadas na constatação unânime de estudos interculturais² de que a escolarização, mais que qualquer outro fator, promoveria transformações no pensamento, gerando diferenças na maneira de enfrentar as tarefas propostas nessas investigações (TULVISTE, 1991).

Na contramão dessa perspectiva, uma nova vertente, construída a partir do final dos anos de 1970, opõe-se radicalmente ao estabelecimento de dicotomias ou à comparação valorativa entre escolarizados e não escolarizados, tornando possível abarcar a complexidade e heterogeneidade da mente humana. ${ }^{3}$ Diversamente, os resultados de estudos fundados nessa perspectiva ${ }^{4}$ têm impelido pesquisadores e educadores à análise de como pessoas não ou pouco escolarizadas operam cognitivamente e participam de práticas sociais, oferecendo importantes informações para que se possa compreender e explicar as estratégias e os procedimentos que elas usam, distintos daqueles mecanismos utilizados pelas pessoas que passaram pelo processo de escolarização e consequentemente dominam a escrita e dela fazem uso. Assim, se socialmente, pessoas pouco ou não escolarizadas podem ter muitos pontos em comum, do ponto de vista de seus patrimônios culturais há mais diferenças e descontinuidades do que uma perspectiva discriminatória tentou demonstrar.

Diferenciam-se no que diz respeito aos ciclos de vida em que estão, às suas identidades, às suas disposições e necessidades formativas, bem como em relação às representações sobre o ler e escrever, os conhecimentos e as habilidades construídos em suas vidas. Dada a heterogeneidade característica desses patrimônios culturais e biografias, articular as especificidades dos sujeitos ao campo da educação escolar é um desafio constante e, com o intuito de contribuir com as reflexões postas neste campo, nos propomos a trabalhar as difíceis relações entre o conhecimento escolar e aqueles que emergem das experiências cotidianas.

\section{Algumas notas sobre a especificidade do conhecimento escolar}

Parafraseando Michael Young, neste ponto do artigo, podemos nos questionar: para que serve a escola para grupos tão heterogêneos do ponto de vista cultural como pessoas jovens e adultas não escolarizadas? Ou melhor, propomo-nos a refletir sobre o modo de realizar escolhas no interior de currículos que devem conectar-se às necessidades educativas de pessoas que percorreram um longo período de suas vidas sem os conhecimentos e práticas sociais compartilhadas no território escolar.

Young (2007), em artigo recente, preocupado com educação escolar de modo amplo, discute o modo como a concepção transmissiva de conhecimento tem sido duramente criticada por pesquisadores da área da educação, pois os críticos apreendem "transmissão" a partir do modelo mecânico, passivo 
e unidirecional de aprendizagem. Para o autor (2007, p. 1293) "a idéia de escolaridade como 'transmissão de conhecimento' dá à palavra transmissão um significado bem diferente e pressupõe explicitamente o envolvimento ativo do aprendiz no processo de aquisição do conhecimento". Ele argumenta que a transmissão de conhecimento que se opera no interior da escola se dá a partir da necessidade de distinguir quais conhecimentos devem ser selecionados para compor o currículo da escola, aqueles que não se encontram disponíveis em outras esferas da vida societal. A delimitação de quais conhecimentos devem ser transmitidos contém a idéia, muitas vezes combatida por educadores, de que existem conhecimentos mais valiosos que outros, e as diferenças formam a base para a categorização do conhecimento curricular ou escolar e do conhecimento não escolar.

Ainda, seguindo o raciocínio do autor, ao contrário do que algumas políticas governamentais propõem, as escolhas por parte dos alunos devem ser relativizadas, pois estes não terão conhecimento prévio para fazer tais escoIhas. Isso não significa desprezar conteúdos trazidos pelos alunos e nem ao menos afirmar que a autoridade do professor é inabalável, mas sim que a escola mantém uma dinâmica que supõe a autoridade de um indivíduo ou de grupos profissionais para a transmissão de conhecimentos que estão fora da esfera do cotidiano, daí a dificuldade em fazer escolhas. Young recoloca o papel dos especialistas, educadores e gestores como sujeitos mais experientes da cultura, sendo capazes e com maiores recursos para fazer certas escolhas quanto à definição dos conhecimentos que entrariam nessa composição que outros sujeitos que desconhecem o papel e o funcionamento escolar.

Com relação às diferenças entre os conhecimentos, Young (2007, p. 1296) difere "conhecimento dependente do contexto" de "conhecimento independente do contexto" e os define:

Um é o conhecimento dependente do contexto, que se desenvolve ao se resolver problemas específicos no cotidiano. Ele pode ser prático, como saber reparar um defeito mecânico ou elétrico, ou encontrar um caminho num mapa. Pode ser procedimental, como um manual ou conjunto de regras de saúde e segurança. O conhecimento dependente do contexto diz a um indivíduo como fazer coisas específicas. Ele não explica ou generaliza; ele lida com detalhes. O segundo tipo de conhecimento é o conhecimento independente do contexto ou conhecimento teórico. É desenvolvido para fornecer generalizações e busca a universalidade. Ele fornece uma base para se fazer julgamentos e é geralmente, mas não unicamente, relacionado às ciências. É esse conhecimento independente de contexto que é, pelo menos potencialmente, adquirido na escola e é a ele que refiro como conhecimento poderoso. 
Esta equação complexa, de quais conhecimentos são relevantes e necessários nos processos de escolarização e de como articular conhecimentos de ordem distintas nos processos de aprendizagem, tem sido um tema bastante discutido no campo da EJA. De acordo com Klein (2003), ao tomar a EJA como ponto de reflexão, "os conteúdos que são objetos dos processos formais de ensino-aprendizagem se caracterizam, em primeiro lugar, pela sua natureza científica", e acrescenta que a função da escolarização é a de proporcionar o domínio básico dos conhecimentos científicos, caracterizando esse processo por meio da transmissão de conhecimento. Essa autora reforça a idéia de que não há equívoco epistemológico ao centrar em certos estágios desse processo, por exemplo, o ensino fundamental, a transmissão de certos conhecimentos (conteúdos). Também se posiciona no sentido de considerar inadequadas as concepções de que o conhecimento científico poderia ser descoberto ou reconstruído por meio da recorrência a conhecimentos produzidos em outras esferas que não a escolar ou científica. A autora afirma que, muitas vezes, ao se fazer a crítica ao denominado ensino tradicional, exacerbam as possibilidades individuais dos alunos e inverte-se o pólo da relação professoraluno, centrando no educando a ênfase do processo pedagógico e esvaziando o papel dos especialistas e educadores na relação ensino-aprendizagem, negando o acesso aos conteúdos científicos, "privilegiando discussões não raro limitadas ao senso comum" (Ibidem, 2006, p. 21).

No sentido de apresentar concepções sobre a especificidade do conhecimento escolar, para pensarmos o desenvolvimento do currículo da EJA, nos parece importante demarcar a idéia de que uma concepção tradicional de conhecimento mostrou-se inadequada ao desenvolvimento dos sistemas escolares e, certamente, não se trata de retomar concepções que, para determinados setores da sociedade, já estão superadas. De acordo com Barreto (2006), a visão tradicional de conhecimento faz uma separação nítida entre fazer e pensar; apresenta uma valorização exagerada da memória, uma necessidade de verbalização excessiva, uma concepção de conhecimento como absoluto; hierarquiza os conhecimentos - transformando diferenças em desigualdades; concentra-se na transmissão verbal do conhecimento; não favorece os alunos da "área popular" e, como decorrência, educa para a submissão. No entanto, já podemos perceber que, ao fazer a crítica ao conhecimento tradicional, a autora já apresenta, em alguns pontos, noções, idéias que tendem a se contrapor aos autores citados acima. Destacamos, por exemplo, a transmissão verbal do conhecimento, reconhecendo que provavelmente daí nasce a falsa impressão muito difundida de que os conhecimentos científicos possam ser simplesmente transmitidos verbalmente. Na verdade, o que é possível transmitir é o discurso sobre o objeto de conhecimento, e como tal, mesmo que em condições altamente hierarquizadas, àquele que recebe o discurso de outrem é dada a possibilidade de réplica e apropriação.

Ribeiro (1999), por sua vez, alerta para o fato de as necessidades práticas geradas na vida cotidiana, ao serem consideradas, não devem compro- 
meter outros aspectos que são peculiares ao processo escolar. Numa posição conciliatória, sustenta ainda a autora que os estudos sobre as especificidades do conhecimento prático ou espontâneo, tendo como contraponto os conhecimentos teóricos, científicos ou escolares, podem subsidiar a ação dos educadores.

A partir dos argumentos já postos, nossos estudos se voltaram à análise de um documento que apresenta uma proposta de currículo para educadores da EJA. O material é direcionado aos professores de uma rede municipal de ensino do estado de São Paulo, construído pela coordenação da área da EJA, em 2004, com a colaboração de educadores, pesquisadores e coordenadores, funcionando como uma diretriz para a ação docente na EJA. Nossas observações tiveram como norte uma leitura mais geral dos textos apresentados com o objetivo de conhecer e discutir a concepção curricular do material e buscar articulá-la com as diversas posições apresentadas nessa unidade.

\section{Problematizando o currículo de Educação de Jovens e Adultos}

A investigação aqui proposta tem como principal interesse conhecer como as discussões do campo da educação de jovens e adultos foram incorporadas na construção de um currículo, especificamente a relação entre os campos do que se convencionou chamar de conhecimentos do cotidiano e de conhecimentos teóricos.

Iniciamos nossa análise discutindo a autoria desta proposta que, diferentemente de processos contemporâneos de construção curricular, tais como a produção dos Parâmetros Curriculares para Educação Nacional, contou com a participação de profissionais da educação inseridos na rede de ensino para a qual ela se destinava. Em vez de equipes ad hoc de especialistas, é da equipe técnica da própria rede municipal, apoiada em discussões com os educadores e equipes gestoras das escolas que atendem a EJA, a autoria desta proposição, o que denota o caráter democrático deste processo.

Outro aspecto importante de nossa análise é a concepção de educação adotada. Fundado nas perspectivas freirianas, divulgadas no Brasil nos anos de 1960, o documento problematiza a educação tradicional, autoritária e "transmissiva", denominada "educação bancária", negando uma posição estritamente conservadora, para assumi-la como "espaço de luta" entre classes sociais. Nesse sentido, no documento reafirma-se que os interesses de uma determinada classe estavam expressos na forma de organização do espaço escolar e, portanto, em seu currículo. Consequentemente, o currículo seria portador de conteúdos selecionados a partir dos interesses de perpetuação da ordem vigente e do statu quo.

Contrapondo-se às visões tradicionais, a concepção de currículo assumida por este grupo está fundada no legado da educação popular e dos movi- 
mentos sociais e, desse modo, trata-se de uma construção política, implicando escolhas muito diversas daquelas prevalentes até então na educação escolar. Explicita também o caráter transitório tanto dos conhecimentos quanto dos problemas postos, opondo-se à idéia corrente de que o conhecimento, principalmente o científico, é absoluto e neutro.

É na seleção de temas abordados na proposta que as questões específicas da EJA aparecem de modo mais explícito: as experiências sociais dos educandos, os percursos e biografias, o mundo do trabalho ${ }^{5}$ e as representações dos educandos são tomados como base das escolhas sobre o que ensinar e como ensinar, garantindo à EJA conteúdos e metodologia próprios.

A preocupação com a articulação entre teoria e prática aparece inclusive como forma de oposição aos aspectos do conhecimento tradicional, já definidos por Barreto, que desvincula o fazer do pensar, reproduzindo, portanto, a divisão entre trabalho manual e intelectual característica das sociedades industriais. Como a divisão existe, ela deve ser tomada como ponto de inflexão, historicizada e, desse modo, desnaturalizada. Ressaltam, ainda, a necessidade de pensar um currículo que possa ser constantemente reorganizado em função do desenvolvimento das práticas educativas, rompendo com a idéia de currículo estável, pronto para ser aplicado e que independe dos sujeitos e contextos nos quais se concretizam. Para a concepção aqui analisada, as especificidades da EJA se dão também no interior do próprio campo, o que significa que o currículo deve reconhecer a riqueza da prática cotidiana e possibilitar que ela possa ser retraduzida para ser incorporada em formas diferenciadas no currículo.

Nesse ponto, problematizamos algumas escolhas feitas. Especialmente, quando se enfatiza que as referências para o trabalho educativo situamse nas práticas diárias dos sujeitos inseridos nas relações escolares e extraescolares e na capacidade de incorporar essas experiências no trabalho pedagógico, como forma de ampliar os horizontes da educação escolar. Considerase, ainda, que a cientifização das explicações do mundo e dos processos sociais legitima a desigualdade da sociedade. Concordamos com Young (2007) que o papel da educação escolar está articulado a um tipo específico de conhecimento, que supõe metodologias igualmente diferenciadas para sua construção e assimilação. No entanto, é fundamental estabelecer que não há por parte do autor uma proposição de neutralidade de um conhecimento, concebendo-o à margem dos conflitos da realidade. Para tanto, observa:

Ao usar a palavra "conhecimento" em termos gerais, considero útil fazer uma distinção entre duas idéias: "conhecimento dos poderosos" e "conhecimento poderoso". O "conhecimento dos poderosos" é definido por quem detém o conhecimento. Historicamente e mesmo hoje em dia, quando pensamos na distribuição do acesso à 
Claudia B. de M. Abreu - Claudia L. Vóvio

\begin{abstract}
universidade, aqueles com maior poder na sociedade são os que têm acesso a certos tipos de conhecimento; é a esse que eu chamo de "conhecimento dos poderosos". É compreensível que muitos críticos sociais do conhecimento escolar equiparem o conhecimento escolar e o currículo ao "conhecimento dos poderosos". [...] No entanto, o fato de que parte do conhecimento é o "conhecimento dos poderosos" ou conhecimento de alto status, como já expressei (YOUNG, 1971; 1998), não nos diz nada sobre o conhecimento em si. Assim, precisamos de outro conceito, no enfoque do currículo, que chamarei de "conhecimento poderoso". Esse conceito não se refere a quem tem mais acesso ao conhecimento ou quem o legitima, embora ambas sejam questões importantes, mas refere-se ao que o conhecimento pode fazer, como, por exemplo, fornecer explicações confiáveis ou novas formas de se pensar a respeito do mundo. (YOUNG, 2007, p. 1294)
\end{abstract}

Permitimo-nos questionar que, ao considerar que a "cientifização das explicações do mundo" está simplesmente posta a serviço da legitimação das diferenças de classes, desconsidera-se o fato de que tais conhecimentos possam ser aqueles "poderosos", "teóricos", que ultrapassam a dimensão imediata das experiências vividas. Nessas escolhas dimensionadas pela equipe de construção curricular parece haver uma generalização excessiva de aspectos ideológicos do currículo, limitando as possibilidades de ascender a conhecimentos capazes de oferecer outros olhares para a própria realidade social dos educandos e compreender as razões de problemas que afetam suas vidas. Isso não significa que não se deva levar em conta as experiências e saberes que os jovens e adultos não ou pouco escolarizados trazem. Young (2007) critica uma visão circular e funcional do currículo escolar e afirma que "não há nenhuma utilidade para os alunos em se construir um currículo em torno da sua experiência, para que este currículo possa ser validado e, como resultado, deixá-los sempre na mesma condição" (YOUNG, 2007, p. 1297). O autor nos alerta para um risco eminente ao se tomar como ponto de referência na organização escolar os conhecimentos e experiências dos educandos, de modo direto e funcional. Podese assumir uma perspectiva discursivamente emancipatória, mas que concretamente pouco avança em relação ao que esses sujeitos já sabem e trazem em suas bagagens culturais.

Com relação aos objetivos específicos e à seleção de conteúdos, estes serão definidos de modo descentralizado, por escolas, resultantes de diagnóstico da realidade social de cada comunidade pelos profissionais da educação. Estabelece-se um conjunto de temas geradores, em uma clara referência às idéias do educador Paulo Freire, que se articulará com as áreas propostas, sendo a categoria trabalho o eixo norteador. Portanto, em relação à organização dos conteúdos, a proposta analisada opõe-se ao suposto caráter científico atri- 
buído ao currículo tradicional, organizado a partir de uma perspectiva multidisciplinar, recorrendo a uma perspectiva totalizante de organização curricular, ordenando-os em rede, contrapondo-se à fragmentação decorrente da organização disciplinar e à linearidade e hierarquização de conteúdos e processos de conhecimento.

Superar a dicotomia entre construção e transmissão, retirando a centralidade dos conteúdos, foi a opção tomada pelo grupo de elaboração curricular. Há nessa escolha uma forte crítica à forma de organização curricular tradicional, cujas características passam pela centralidade dos conteúdos e pela rigidez nas formas de desenvolvimento das aulas, em uma generalização talvez um pouco forçada. Considera que os conteúdos tradicionais são os saberes úteis ao mercado e, em função disto, tornaram-se mais nobres do que outros saberes. Segundo o documento, a organização do ensino na sua forma fechada, quantificável, científico-escolar é mais tranquila. Nesse caso é preciso pensar que as tensões também estiveram e estão presentes no cotidiano das organizações escolares mais conservadoras; que as formas de avaliar, encaminhar as aulas, os conteúdos trabalhados não ficaram imunes às diferentes formas de resistência, tanto dos educandos quanto dos próprios educadores.

Ainda como expressão das discussões para a construção do currículo para a EJA, o grupo de construção curricular propõe a organização do ensino na forma de ciclos para o ensino fundamental. Seu objetivo é tornar a avaliação do processo de ensino-aprendizagem mais flexível a fim de abarcar os diferentes ritmos e tempos dos educandos jovens e adultos, o que não ocorreria em uma estrutura seriada e classificatória.

Observamos na análise a tensão posta para este campo educacional. De um lado, busca-se abarcar as versões da cultura e os conhecimentos cotidianos e relacionados à realidade social dos educandos. Por outro, minimizam-se aqueles que de modo hegemônico têm sido tomados como basilares para formação escolar, de caráter científico e descontextualizados. O currículo produzido por esta equipe coloca-se em consonância com o legado da educação popular, horizontalizando-se os diferentes conhecimentos a serem adquiridos e estabelecendo continuidades entre o primeiro e o segundo. No entanto, questionamos se tal mediação se torna possível no território da educação escolar, marcado mais por descontinuidades entre esses conhecimentos do que por aproximações.

\section{Considerações finais e perspectivas}

A partir do que apresentamos é importante ressaltar que esta análise serviu como exercício para pesquisas futuras sobre as implicações da assunção de certos pressupostos para a organização de currículos da educação de jovens e adultos, das diferentes formas de conceber o espaço escolar, assim como definir qual é o modo mais adequado de tratar as especificidades do conheci- 
mento, de forma que a educação escolar dos jovens e adultos alcance os resultados desejados.

No pequeno exercício que aqui fizemos, tentamos apontar para possíveis confrontos sobre os significados da distinção entre conhecimento escolar e não escolar. Abordamos também a necessidade de se rever questões sobre a transmissão e a construção de conhecimentos, do papel do professor, da difícil relação entre experiência e teoria, enfim, das discussões que envolvem a construção de currículo.

Para finalizar, enfatizamos um ponto que auxilia a pensar sobre currículo para área, quer seja, a idéia das necessidades de aprendizagem. Para jovens e adultos, na condição de trabalhadores, as necessidades de aprendizagem funcionam como um fator de motivação, por isso "a educação de jovens e adultos obriga os educadores a focalizar sua ação pedagógica no presente, enfrentando de forma mais radical a problemática envolvida na combinação entre formação geral e profissional, entre teoria e prática, universalismo e contextualização etc." (RIBEIRO, 1999, p. 193-194).

\section{Referências}

ARROYO, M. G. Educação de jovens e adultos: um campo de direitos e de responsabilidade pública. In: SOARES, L. J. G.; GIOVANETTI, M. A.; GOMES, N. L. Diálogos na educação de jovens e adultos. Belo Horizonte: Autêntica, 2005. p. 19-50.

BARRETO, V. O processo de aprendizagem dos alunos e professores. Trabalhando com a Educação de Jovens e Adultos. Ministério da Educação. SECAD: Brasília, 2006.

DI PIERRO, M. C. Notas sobre a redefinição da identidade e das políticas públicas de educação de jovens e adultos no Brasil. Educação \& Sociedade, Campinas, v. 26, n. 92, p. 1115-1139, 2005.

COSTA, M. V. Currículo e política cultural. In: limiar do contemporâneo. Rio de Janeiro: $\mathrm{DP \& A}, 1998$.

INSTITUTO BRASILEIRO DE GEOGRAFIAE ESTATÍSTICA-IBGE. Pesquisa nacional para amostra de domicílios - PNAD, 2007.

HADDAD, S. Por uma nova cultura na Educação de Jovens e Adultos, um balanço de experiências do poder local. 30 ${ }^{\mathrm{a}}$ Reunião Anual da Anped, Caxambu, 2007, p. 1-30.

KALMAN, J.¿Somos lectores o no? Una revisión histórica del concepto de alfabetización y sus consecuencias. In: INEA. Lecturas para la educación de los adultos: aportes de fin de siglo. t. III. México: INEA, 2000. p. 91-143. 
KLEIMAN, A. Os significados do letramento. Campinas: Mercado das Letras, 1995. $295 \mathrm{p}$.

KLEIN, L. R. Alfabetização de jovens e adultos. Questões e propostas para a prática pedagógica na perspectiva histórica. Brasília: Universa, 2003.

LURIA, A. R. Desenvolvimento cognitivo: seus fundamentos sociais e culturais. São Paulo: Ícone, 1990.

OLIVEIRA, M. K. Organização conceitual em adultos pouco escolarizados. In: OLIVEIRA, M. K.; OLIVEIRA, M. B. (Orgs.). Investigações cognitivas: conceitos, linguagem e cultura. Porto Alegre: Artes Médicas, 1999. p. 81-100.

RIBEIRO, V. M. A formação de educadores e a constituição da educação de jovens e adultos como campo pedagógico. Educação e Sociedade, ano XX, n. 68, 1999.

SOARES, M. Letramento: um tema em três gêneros. Belo Horizonte: Autêntica, 1998. $125 \mathrm{p}$.

STREET, B. V. Literacy in theory and practice. Cambridge: Cambridge University Press, 1984.

TULVISTE, P. The cultural-historical development of verbal thinking. New York: Nova Science, 1991.

YOUNG, M. Para que servem as escolas. Educação e Sociedade, v. 108, n. 101, p. 1287-1302, set./dez. 2007.

\section{Notas}

${ }^{1} \mathrm{O}$ termo atraso encontra-se entre aspas pois, em nossa sociedade, um dos discursos correntes é o de que as crianças e adolescentes devam ocupar os bancos escolares. A impossibilidade de acessar e permanecer em processos de escolarização são muitas vezes tomados como de responsabilidade dos indivíduos, como um problema de atraso a ser compensado na vida adulta, de modo abreviado.

${ }^{2}$ Além de Tulviste, consultar Luria (1990), Oliveira (1999) e Street (1984), entre outros.

3 Ver Oliveira (1999) em seus estudos sobre jovens e adultos urbanos não escolarizados e Kleimam (1995) e Soares (1998) que organizaram uma revisão abrangente do conceito e pesquisas sobre letramento.

${ }^{4}$ Ver Street (1984).

${ }^{5}$ Os educandos de EJA são, em sua maioria, trabalhadores (às vezes, desempregados) ou são filhos de trabalhadores. As condições de trabalho desse grupo podem variar muito, mas tendem a ser precárias. 
Claudia B. de M. Abreu - Claudia L. Vóvio

\section{Correspondência}

Claudia Barcelos de Moura Abreu - Rua Apiacás, 570, ap. 21, CEP 05017-020, São Paulo (SP).

E-mail: claudia.abreu@unifesp.br

Recebido em 28 de outubro de 2009

Aprovado em 15 de fevereiro de 2010 